\title{
Polymer in Sustainable Energy
}

\author{
Darshan Patel, Suresh P. Deshmukh* \\ General Engineering Department, Institute of Chemical Technology, Mumbai, India \\ Email: darshan016@gmail.com, "sp-deshmukh@yahoo.co.in
}

Received January 15, 2012; revised February 22, 2012; accepted March 9, 2012

\begin{abstract}
A transparent polymer based solar cell was designed and fabricated to utilize the solar energy when exposed to sunlight. The transparent solar cell for window module was composed of a polymeric material PPV (Polyphenylene vinylene), ITO (Indium Tin Oxide) and electrode ( $\mathrm{Al}, \mathrm{Mg}, \mathrm{Ca}$ ). The polymeric sheet of this cell is by casting process, and electrode is applied on it by CVD (Chemical Vapor Deposition) process. The solar energy collected by this window can be used to power up small household electrical appliances. Recently, polymeric solar cell is made by a roll-to-roll process without using indium-tin oxide (ITO). A commercially available kapton (Polyimide) foil with an over layer of copper was used as the substrate. Sputtering of titanium metal on to the kapton/copper in a vacuum metalizing process gave the monolithic substrate and back electrode for the devices. The active layer was slot-die coated on to the kapton/Cu/Ti foil followed by slot-die coating of a layer of PET, PC or PEN.
\end{abstract}

Keywords: Organic Solar Cells; Organic Photovoltaics; ITO-Free; Current Collecting Grid; Printed Anode; High Conductive PEDOT:PSS; Polymer Solar Cells

\section{Introduction}

There is increasing awareness for developing renewable energy sources in the world as the oil reserves will finally run out in future. Many countries are planning to increase the contribution of renewable energies in total energy supply. Earth heat, wind and ocean energy are examples of sustainable or renewable energy sources under investigation [1-4]. However, the utilization of sunlight seems to be the most popular and practical approach for renewable energy realization [5]. Solar energy can be directly converted to electrical energy by solar cells. How to trap and use efficiently this huge energy reservoir from the sun becomes a major challenge for mankind. There are different kinds of solar cells being developed such as silicon solar cells [6-8], dye-sensitized solar cell (DSC) [9-11], organic polymer solar cells [12], hybrid solar cells $[13,14]$ and CIGS solar cells $[15,16]$. With its high solar energy conversion efficiency and mature fabrication technologies, nowadays silicon solar cell is the most extensively used type of cell. In addition, conventional silicon solar cells convert between $10 \%$ and $15 \%$ of the sun's energy into electricity.

Fossil fuel alternatives, such as solar energy, are moving to the forefront in a variety of research fields. Polymer-based organic photovoltaic systems hold the promise for a cost-effective, lightweight solar energy conversion platform, which could benefit from simple solution proc-

${ }^{*}$ Corresponding author. essing of the active layer and the very high production speeds that can be reached by roll-to-roll printing and coating techniques [17-22]. The function of such excitonic solar cells is based on photo induced electron transfer from a donor to an acceptor. Fullerenes have become the ubiquitous acceptors because of their high electron affinity and ability to transport charge effectively. The most effective solar cells have been made from bicontinuous polymer-fullerene composites, or so-called bulk hetero-junctions. The best solar cells currently achieve an efficiency of about $5 \%$, thus significant advances in the fundamental understanding of the complex interplay between the active layer morphology and electronic properties are required if this technology is to find viable application.

Indium-tin oxide (ITO), which is commonly used as a transparent electrode, is one of the main cost consuming elements in present photovoltaic devices [17-23]. The second argument to omit ITO from OPV devices is mechanical flexibility. The brittle ITO layer can be easily cracked, leading to a decrease in conductivity and as a result degradation of the device performance. A third argument is the multi-step patterning of the ITO layer, which involves a lot of chemicals. A lot of effort has been directed on the development of highly conductive polymeric materials such as poly(3,4-ethylenedioxythiophene):poly(4-styrenesulphonate) (PEDOT:PSS). Replacement of ITO by highly conductive PEDOT:PSS has been intensively studied by many researchers [24-28]. How- 
ever, organic photovoltaic devices with only a PEDOT: PSS electrode do not provide high efficiency for large area devices due to the limited conductivity of the PEDOT:PSS, which is typically up to $500 \mathrm{~S} \cdot \mathrm{m}^{-1}$. Improving the conductivity of such a polymeric electrode is possible by combining it with a metal grid, which is either thermally evaporated through micro structured shadow masks $[29,30]$ or patterned by a lithographic method [31,32]. In Ref. [33] deposition of an Ag grid by diffusion transfer reversal has been reported. Printing of the metal grid, however, is a prerequisite for fully printed OPV devices, enabling low-cost manufacturing. Screen printed silver grids [20] were demonstrated in a roll-to-roll processed inverted OPV device, where the grid is the last printed layer in the devices. Earlier, it has been reported that, inkjet printed current collecting grids was a part of a composite anode in a conventional OPV device [33], where the grid is the first printed layer in the devices.

\section{Optimization of Organic Solar Cells on the Basis of Mechanistic Principles}

Efforts to optimize the performance of organic solar cells have found their basis in the fundamental mechanism of operation. Scheme 1 illustrates the mechanism by which light energy is converted into electrical energy in the devices. The energy conversion process has four fundamental steps in the commonly accepted mechanism [34]: 1) Absorption of light and generation of excitons; 2) diffusion of the excitons; 3) dissociation of the excitons with generation of charge; and 4) charge transport and charge collection. Figure 1 shows a schematic representation of a typical BHJ solar cell, illustrating the components involved in the mechanistic steps as well as a current-voltage curve defining the primary quantities used to validate the performance of a solar cell. The elementary steps involved in the pathway from photo excitation to the generation of free charges are shown in Scheme 2. $[35,36]$ The processes can also occur in an analogous fashion in the case of an excited acceptor, and the details of these mechanistic steps have been described extensively in the literature [37]. The key point is that electron transfer is not as simple as depicted in Scheme 1. The process must be energetically favorable to form the geminate pair in step 3 of Scheme 2 and an energetic driving force must exist to separate this Coulombically bound electron-hole pair.

Figure 1 shows the schematic illustration of a polymer-fullerene BHJ solar cell, with a magnified area showing the bicontinuous morphology of the active layer. ITO is indium tin oxide and PEDOT-PSS is poly(3,4-ethylenedioxythiophene)-polystyrene sulfonate. The typical current-voltage characteristics for dark and light current in a solar cell illustrate the important parameters for such devices: $J_{S C}$ is the short-circuit current density, $V_{o c}$ is the open circuit voltage, $J_{m}$ and $V_{m}$ are the current and voltage at the maximum power point, and $\mathrm{FF}$ is the fill factor. The efficiency $(h)$ is defined, both simplistically as the ratio of power out $\left(P_{\text {out }}\right)$ to power in $\left(P_{\text {in }}\right)$, as well as in terms of the relevant parameters derived from the current-voltage relationship.

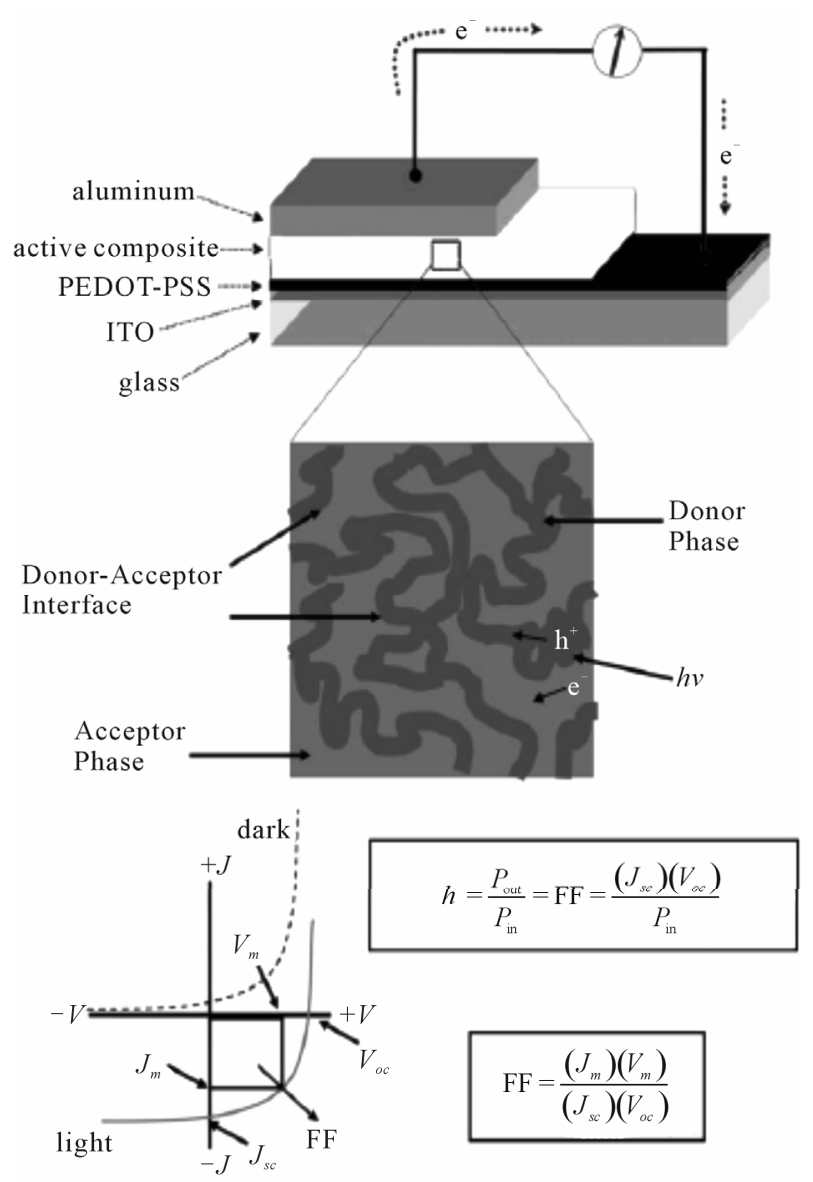

Figure 1. Polymer-fullerence BHS solar cell.

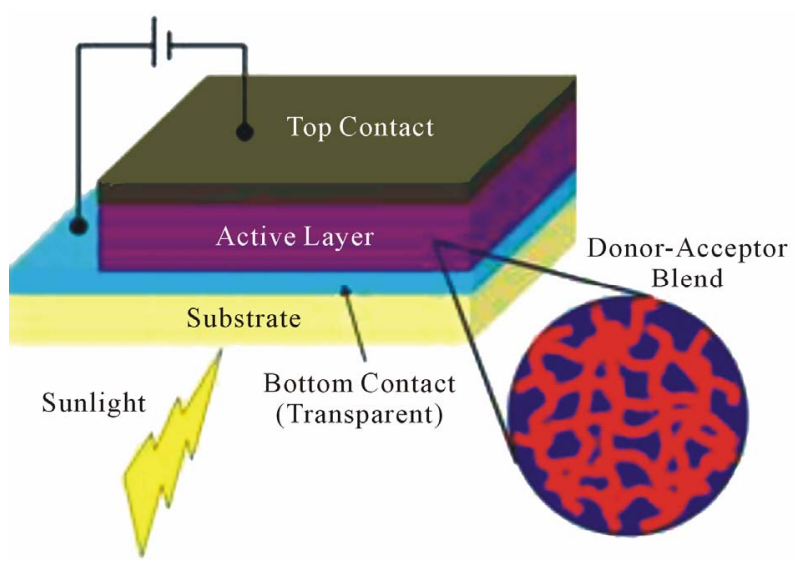

Scheme 1. Mechanism of energy conversion. 


\begin{tabular}{|c|c|}
\hline 1 & $D+A \stackrel{h v}{\longrightarrow} D^{*}+A$ \\
\hline 2 & $D^{*}+A \leftrightarrow\left[D^{*}, A\right]$ \\
\hline 3 & {$\left[D^{*}, A\right] \leftrightarrow\left[D^{+*},+A^{-*}\right]$} \\
\hline 4 & {$\left[D^{+*}+A^{-*}\right] \leftrightarrow D^{+*}, A^{-*}$} \\
\hline
\end{tabular}

Scheme 2. Elementary steps in the process of photoinduced charge separation for a donor $(D)$ and an acceptor $(A): 1)$ Photoexcitation of the donor; 2 ) Diffusion of the exciton and formation of an encounter pair; 3) Electron transfer within the encounter pair to form a geminate pair; 4) Charge separation.

It is apparent that the active layer donor-acceptor composite governs all aspects of the mechanism, with the exception of charge collection, which is based on the electronic interface between the active layer composite and the respective electrode. Detailed descriptions of the steps used for device fabrication are found elsewhere [38]. Besides the fundamental mechanistic steps, the open circuit voltage $\left(\mathrm{V}_{\mathrm{oc}}\right)$ is also governed by the energetic relationship between the donor and the acceptor (Scheme 1) rather than the work functions of the cathode and anode, as would be expected from a simplistic view of these diode devices. Specifically, the energy difference between the donor and the acceptor is found to most closely correlate with the $\mathrm{V}_{\text {oc }}$ value $[39,40]$.

It is therefore apparent that the choice of the components in the active layer as well as its morphology, which governs the physical interaction between the donor and acceptor, are the primary factors affecting the performance of the device. As such, the focus of this Review is the optimization and understanding of the electronic and physical interactions between polymeric donors and fullerene acceptors in BHJ solar cells. Architectural modification (such as the use of buffer layers) or the choices of electrodes are also critical aspects which will be viewed as a second level of device optimization in our discussion.

\section{Manufacturing Technique}

A series of organic solar cell devices were prepared on flexible PET substrates. The layouts of the ITO-based and ITO-free devices are shown in Figure 2.

Low conductive PEDOT:PSS was used for the preparation of the ITO-based devices. The PEDOT:PSS was spin coated at $2000 \mathrm{rpm}$, resulting in a dry layer thickness of $40 \mathrm{~nm}$ after baking at $1501 \mathrm{C}$ for $10 \mathrm{~min}$. For the devices free from ITO, the highly conductive PEDOT: PSS was used. Highly conductive PEDOT:PSS was spin coated at $800 \mathrm{rpm}$, resulting in a dry layer thickness of $100 \mathrm{~nm}$. Poly(3-hexylthiophene; P3HT and [6,6]-phenylC61-butyric acid methyl ester (PCBM) (99\%) were dis- solved in 1,2-dichlorobenzene with a mixing ratio of 1:1 by weight. The solution was stirred for $14 \mathrm{~h}$ at $70^{\circ} \mathrm{C}$. The photoactive layers were obtained by spin coating of the blend with $4 \mathrm{wt} \%$ of the active materials at $1000 \mathrm{rpm}$ for $30 \mathrm{~s}$, which corresponds to a thickness of $220 \mathrm{~nm}$. The thicknesses of the films were measured using a Dektak profilometer. The experiments are performed in a clean room environment at ambient atmosphere. The metal cathode ( $1 \mathrm{~nm} \mathrm{LiF}, 100 \mathrm{~nm} \mathrm{Al})$ was thermally evaporated in a vacuum chamber through a shadow mask. The OPV devices were finished by thin film encapsulation in a glove box. A picture of the device with current collecting grid is shown in Figure 3.

Current-voltage curves were measured using simulated AM 1.5 global solar irradiation $\left(100 \mathrm{~mW} / \mathrm{cm}^{2}\right)$, using a xenon-lamp-based solar simulator Oriel (LS0104) $150 \mathrm{~W}$. The light source was calibrated with a standard Si photodiode detector. UV-vis transmission/absorption spectra were measured using a Perkin-Elmer Lambda 12 UV/vis spectrophotometer.

Figure 4(a) shows a picture of a typical part of a screen printed honeycomb current collecting grid, which is part of the composite anode. The corresponding line profile as shown in Figure 4(b) is relatively smooth. The effective line width was $160 \mu \mathrm{m}$, which is a very good match with the theoretically expected value.

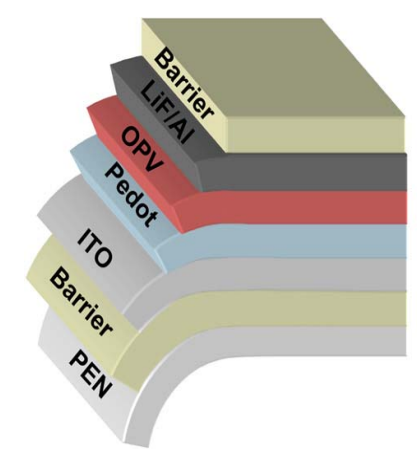

(a)

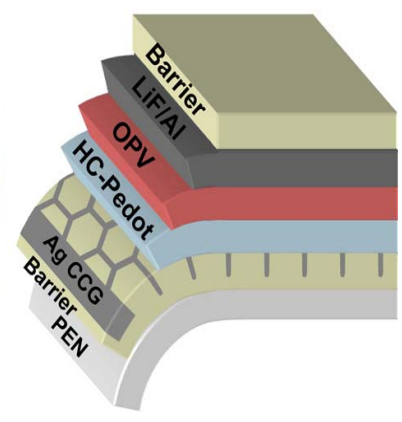

(b)
Figure 2. Schematic illustration of an ITO-based device and a device with a current collecting grid.

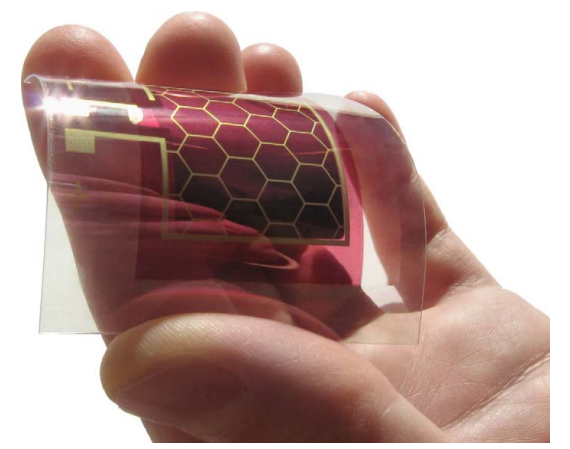

Figure 3. A picture of the $2 \times 2 \mathrm{~cm}^{2}$ device with current collecting grid, free from ITO. 


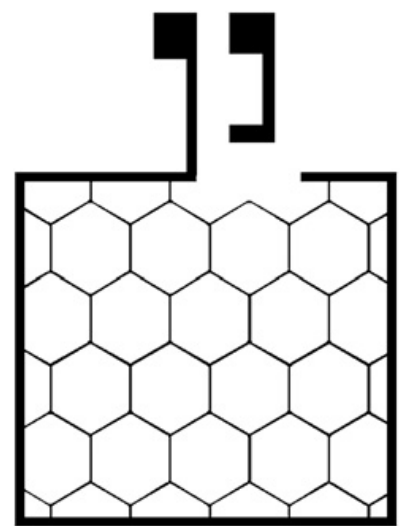

(a)

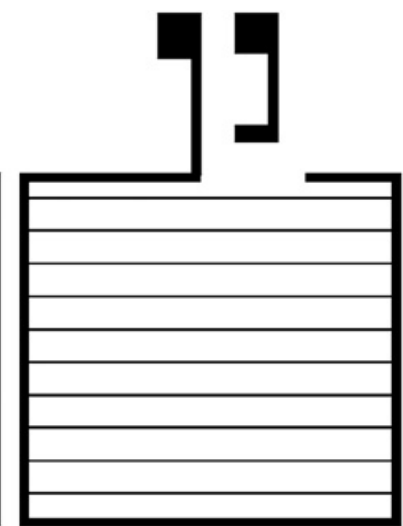

(b)
Figure 4. Conductive grids: (a) with honeycomb and (b) line patterns used for the $2 \times 2 \mathrm{~cm}^{2}$ devices.

Honeycomb structure provides more aesthetic view of the devices. Moreover, this structure provides homogeneous current distribution in case of four bus-bar devices, which were used in this study. Line pattern of the grid, which is more applicable for module design, has been compared with honeycomb structure. In this study the pitch sizes (the minimum distance between two conducting lines) and grid's surface coverage were compared. The pitch size was 5 and $2 \mathrm{~mm}$ and surface coverage was $6.4 \%$ and $8 \%$ for the honeycomb and line patterns, respectively.

\section{Conclusions}

Replacing ITO by a composite anode consisting of combination of a metal grid and HC-PEDOT results in a significant increase in efficiency for devices of $2 \times 2 \mathrm{~cm}^{2}$ area. Future work will concentrate in maximizing the cell area without substantial efficiency losses using optimized grid structures. This will enable a substantial increase of the active area of OPV modules, which in turn will increase the final $\mathrm{Wp} / \mathrm{m}^{2}$.

The shadow effect of the grids contributes to the lower current density in the ITO-free devices. The sum of all these factors explains why the current density in ITObased and ITO-free devices is different. Further improvement of the current density in ITO-free devices is possible by decreasing the shadow effect, by minimizing the line width in the grids and by increasing the transparency of the high conductive PEDOT and optimization of layer thicknesses. The $100 \mathrm{~nm}$ thick layer of high conductive PEDOT has a relatively high absorption in the visible region. Replacing the ITO by a high conductive PEDOT:PSS (HC-PEDOT) leads to a decrease of the short-circuit current [18]. The result of with ITO and ITO-free is shown in Table 1.

Organic solar cells free from ITO on flexible substrates were fabricated. The alternative anode is based on
Table 1. Characteristics of photovoltaic devices.

\begin{tabular}{ccc}
\hline Anode & $\left(\mathrm{mA} / \mathrm{cm}^{2}\right)$ & Volts \\
\hline ITO & 6.59 & 0.489 \\
Ag Honeycomb/HC-PEDOT & 6.25 & 0.540 \\
Ag lines/HC-PEDOT & 6.36 & 0.540 \\
\hline
\end{tabular}

highly conductive PEDOT:PSS in combination with printed current collecting grids. This type of composite anode has a significantly lower sheet resistance in comparison with ITO, which makes larger area devices possible without substantial efficiency losses. The experiments show that the replacement of ITO by a composite anode yields an efficiency increase by a factor of two for devices with an active area of $2 \times 2 \mathrm{~cm}^{2}$. Moreover, the anode is entirely fabricated with solution processing and does not require high temperature annealing nor litho steps. All temperature treatments are compatible with flexible substrates and roll-to-roll processing. Free from the rather expensive vacuum deposited ITO, the composite electrode can significantly decrease manufacturing cost. This work will ultimately contribute towards fully printed devices, which will provide low-cost roll-to-roll manufacturing.

\section{REFERENCES}

[1] E. Barbier, "Geothermal Energy Technology and Current Status: An Overview," Renewable and Sustainable Review, Vol. 6, No. 1-2, 2002, pp. 3-65. doi:10.1016/S1364-0321(02)00002-3

[2] A. D. Sahin, "Progress and Recent Trends in Wind Energy," Progress in Energy and Combustion Science, Vol. 30, No. 5, 2004, pp. 501-543.

doi:10.1016/i.pecs.2004.04.001

[3] D. Barry, "Renewable Energy as a Natural Gas Price Hedge: The Case of Wind," Energy Policy, Vol. 33, No. 6, 2005, pp. 799-807. doi:10.1016/j.enpol.2003.10.005

[4] R. Pelc and R. M. Fujita, "Renewable Energy from the Ocean," Marine Policy, Vol. 26, No. 6, 2002, pp. 471-479. doi:10.1016/S0308-597X(02)00045-3

[5] Y. Tsur and A. Zemel, "Long-Term Perspective on the Development of Solar Energy," Solar Energy, Vol. 68, No. 5, 2000, pp. 379-392.

doi:10.1016/S0038-092X(00)00018-9

[6] S. Reber, W. Zimmermann and T. Kieliba, "Zone Melting Recrystallization of Silicon Films for Crystalline Silicon Thin-Film Solar Cells," Solar Energy Materials and Solar Cells, Vol. 65, No. 1-4, 2001. pp. 409-416. doi:10.1016/S0927-0248(00)00120-3

[7] M. A. Green, "Crystalline and Thin-Film Silicon Solar Cells: State of the Art and Future Potential," Solar Energy, Vol. 74, No. 3, 2003, pp. 181-192. doi:10.1016/S0038-092X(03)00187-7

[8] J. Zhao, "Recent Advances of High-Efficiency Single 
Crystalline Silicon Solar Cells in Processing Technologies and Substrate Materials," Solar Energy Materials and Solar Cells, Vol. 82, No. 1-2, 2004, pp. 53-64. doi:10.1016/j.solmat.2004.01.005

[9] R. D. McConnell, "Assessment of the Dye-Sensitized Solar Cell," Renewable and Sustainable Review, Vol. 6, No. 3, 2002, pp. 273-295.

[10] M. Gratzel, "Dye-Sensitized Solar Cells," Journal of Photochemistry and Photobiology C: Photochemistry Reviews, Vol. 4, No. 2, 2003, pp. 145-153. doi:10.1016/S1389-5567(03)00026-1

[11] S. Anandan, "Recent Improvements and Arising Challenges in Dye-Sensitized Solar Cells," Solar Energy Materials and Solar Cells, Vol. 91, No. 9, 2007, pp. 843846. doi:10.1016/j.solmat.2006.11.017

[12] H. Spanggaard and F. C. Krebs, "A Brief History of the Development of Organic and Polymeric Photovoltaics," Solar Energy Materials and Solar Cells, Vol. 83, No. 2-3, 2004, pp. 125-146. doi:10.1016/j.solmat.2004.02.021

[13] J. Ackermann, C. Videlot and A. El Kassmi, "Growth of Organic Semiconductors for Hybrid Solar Cell Application," Thin Solid Films, Vol. 403-404, 2002, pp. 157-161. doi:10.1016/S0040-6090(01)01578-4

[14] E. Arici, H. Hoppe, F. Schaffler, D. Meissner, M. A. Malik and N. S. Sariciftci, "Hybrid Solar Cells Based on Inorganic Nanoclusters and Conjugated Polymers," Thin Solid Films, Vol. 451-452, 2004, pp. 612-618. doi:10.1016/j.tsf.2003.11.026

[15] T. Wada, Y. Hashimoto, S. Nishiwaki, T. Satoh, S. Hayashi, T. Negami and H. Miyake, "High-Efficiency CIGS Solar Cells with Modified CIGS Surface," Solar Energy Materials and Solar Cells, Vol. 67, No. 1-4, 2001, pp. 305-310. doi:10.1016/S0927-0248(00)00296-8

[16] F. Kessler and D. Rudmann, "Technological Aspects of Flexible CIGS Solar Cells and Modules," Solar Energy, Vol. 77, No. 6, 2004, pp. 685-695. doi:10.1016/j.solener.2004.04.010

[17] F. C. Krebs, "Roll-to-Roll Fabrication of Monolithic LargeArea Polymer Solarcells Free from Indium-Tin-Oxide, Solar Energy Materials and Solar Cells, Vol. 93, No. 9, 2009, pp. 1636-1641. doi:10.1016/j.solmat.2009.04.020

[18] Y. Galagan, I. G. de Vries, A. Langen, R. Andriessen, W. Verhees, S. Veenstra and J. Kroon, "Technology Development for Roll-to-Roll Production of Organicphotovoltaics," Chemical Engineering and Processing: Process Intensification, Vol. 50, No. 5-6, 2010, pp. 454-461. doi:10.1016/j.cep.2010.07.012.

[19] F. C. Krebs, "Fabrication and Processing of Polymer Solar Cells: A Reviewof Printing and Coating Techniques," Solar Energy Materials and Solar Cells, Vol. 93, No. 4, 2009, pp. 394-412. doi:10.1016/j.solmat.2008.10.004

[20] F. C. Krebs, "Polymer Solar Cell Modules Prepared Using Roll-to-Roll Methods: Knife-over-Edge Coating, SlotDie Coating and Screen Printing," Solar Energy Materials and Solar Cells, Vol. 93, No. 4, 2009, pp. 465-475. doi:10.1016/j.solmat.2008.12.012

[21] L. Blankenburg, K. Schultheis, H. Schache, S. Sensfuss and M. Schrödner, "Reel-to-Reel Wet Coating as an Effi- cient Up-Scaling Technique for the Production of BulkHeterojunction Polymer Solar Cells," Solar Energy Materials and Solar Cells, Vol. 93, No. 4, 2009, pp. 476483. doi:10.1016/j.solmat.2008.12.013

[22] A. J. Medford, M. R. Lilliedal, M. Jørgensen, D. Aarø, H. Pakalski, J. Fyenbo and F. C. Krebs, "Grid-Connected Polymer Solar Panels: Initial Considerations of Cost, Lifetime, and Practicality," Optics Express, Vol. 18, No. 53, 2010, pp. A272-A285. doi:10.1364/OE.18.00A272

[23] F. C. Krebs, T. Tromholt and M. Jorgensen, "Upscaling of Polymer Solar Cellabrication Using Full Roll-to-Roll Processing," Nanoscale, Vol. 2, No. 6, 2010, pp. 873-886. doi:10.1039/b9nr00430k

[24] Y. Zhou, F. Li, S. Barrau, W. Tian, O. Inganäs and F. Zhang, "Inverted and Transparentpolymer Solar Cells Prepared with Vacuum-Free Processing," Solar Energy Materials and Solar Cells, Vol. 93, No. 4, 2009, pp. 497500. doi:10.1016/j.solmat.2008.11.002

[25] S. K. Hau, H.-L. Yip, J. Zou and A. K. Y. Jen, "Indium Tin Oxide-Free Semi-Transparent Inverted Polymer Solar Cells Using Conducting Polymer as both Bottom and Top Electrodes," Organic Electronics, Vol. 10, No. 7, 2009, pp. 1401-1407. doi:10.1016/j.orgel.2009.06.019

[26] B. Winther-Jensen and F .C. Krebs, "High-Conductivity Large-Area Semi-Transparentelectrodes for Polymer Photovoltaics by Silk Screen Printing and Vapour-Phasedeposition," Solar Energy Materials and Solar Cells, Vol. 90, No. 2, 2006, pp. 123-132.

doi:10.1016/j.solmat.2005.02.004

[27] E. Ahlswede, W. Muhleisen, M. W. bin Moh Wahi, J. Hanisch and M. Powalla, "Highlyefficient Organic Solar Cells with Printable Low-Cost Transparent Contacts," Applied Physics Letters, Vol. 92, No. 14, 2008, p. 143307. doi:10.1063/1.2907564

[28] Y.-M. Chang, L. Wang and W.-F. Su, "Polymer Solar Cells with Poly(3,4-ethylenedioxythiophene) as Transparent Anode," Organic Electronics, Vol. 9, No. 6, 2008, pp. 968-973. doi:10.1016/i.orgel.2008.07.003

[29] M. Glatthaar, M. Niggemann, B. Zimmermann, P. Lewer, M. Riede, A. Hinsch and J. Luther, "Organic Solar Cells Using Inverted Layer Sequence," Thin Solid Films, Vol. 491, No. 1-2, 2005, pp. 298-300. doi:10.1016/j.tsf.2005.06.006

[30] B. Zimmermann, M. Glatthaar, M. Niggemann, M. K. Riede, A. Hinsch and A. Gombert, "ITO-Free Wrap through Organic Solar Cells-A Module Conceptfor Cost-Efficient Reel-to-Reel Production," Solar Energy Materials and Solar Cells, Vol. 91, No. 5, 2007, pp. 374-378. doi:10.1016/j.solmat.2006.10.005

[31] K. Tvingstedt and O. Inganäs, "Electrode Grids for ITO Free Organic Photovoltaicdevices," Advanced Materials, Vol. 19, No. 19, 2007, pp. 2893-2897. doi:10.1002/adma.200602561

[32] J. Zou, H.-L. Yip, S. K. Hau and A. K. Y. Jen, "Metal Grid/Conducting Polymer Hybridtransparent Electrode for Inverted Polymer Solar Cells," Applied Physics Letters, Vol. 96, No. 20, 2010, pp. 203301-203303. doi:10.1063/1.3394679

[33] T. Aernouts, P. Vanlaeke, W. Geens, J. Poortmans, P. He- 
remans, S. Borghs, R. Mertens, R. Andriessen and L. Leenders, "Printable Anodes for Flexible Organicsolar Cell Modules," Thin Solid Films, Vol. 451-452, 2004, pp. 22-25. doi:10.1016/i.tsf.2003.11.038

[34] Y. Galagan, R. Andriessen, E. Rubingh, N. Grossiord, P. Blom, S. Veenstra, W. Verhees and J. Kroon, "Toward Fully Printed Organic Photovoltaics: Processingand Stability," Holst Centre, Eindhoven, 2010, pp. 88-91.

[35] C. J. Brabec, N. S. Sariciftci and J. C. Hummelen, "Plastic Solar Cells," Advanced Functional Materials, Vol. 11, No. 1, 2001, pp. 15-26. doi:10.1002/1616-3028(200102)11:1<15::AID-ADFM15 $>3.0 . \mathrm{CO} ; 2-\mathrm{A}$

[36] R. Koeppe and N. S. Sariciftci, "Photoinduced Charge and Energy Transfer Involving Fullerene Derivatives," Photochemical \& Photobiological Sciences, Vol. 5, No. 12, 2006, pp. 1122-1131. doi:10.1039/b612933c

[37] M. A. Fox and M. Chanon, "Photoinduced Electron Trans- fer," Elsevier, Amsterdam, 1988.

[38] H. Hoppe and N. S. Sariciftci, "Organic Solar Cells: An Overview," Journal of Materials Research, Vol. 19, No. 7, 2004, pp. 1924-1945. doi:10.1557/JMR.2004.0252

[39] C. J. Brabec, A. Cravino, D. Meissner, N. S. Sariciftci, T. Fromherz, M. T. Rispens, L. Sanchez and J. C. Hummelen, "Origin of the Open Circuit Voltage of Plastic Solar Cells," Advanced Functional Materials, Vol. 11, No. 5, 2001, pp. 374-380. doi:10.1002/1616-3028(200110)11:5<374::AID-ADFM3 74>3.0.CO;2-W

[40] A. Gadisa, M. Svensson, M. R. Andersson and O. Inganas, "Correlation between Oxidation Potential and Open-Circuit Voltage of Composite Solar Cells Based on Blends of Polythiophenes/Fullerene Derivative," Applied Physics Letters, Vol. 84, No. 9, 2004, pp. 1609-1611. doi:10.1063/1.1650878 